\title{
Wind-induced pressure loads on buildings in tandem arrangement in urban environment
}

\author{
Renata Gnatowska ${ }^{1}$ id
}

Received: 18 February 2018 / Accepted: 2 November 2018 / Published online: 10 November 2018

(c) The Author(s) 2018

\begin{abstract}
The wind-induced pressure loads are affected by a broad spectrum of elements involving flow conditions, buildings geometry, or neighbourhoods. Computational fluid dynamics is a useful device used to estimate pressure distribution. The aim of this research is a detailed assessment of the use of numerical calculation (RANS) for forecasting wind-induced pressure loads on buildings arranged in tandem located in the built-up area. The approach of this work was to determine the pressure loads on the walls of rectangular objects, which were the simplified models of buildings located in the ground-level zone. The important task was to estimate the impact of distance between obstacles on the pressure loads on their surfaces. It was found that when changing the distance between buildings the pressure distribution on the downstream object varies significantly. Additionally, for defined geometrical parameters, the influence of inflow angle was analysed. The obtained results demonstrate and confirm that RANS numerical calculations, in spite of all their limits, can accurately modeling the pressure distribution on buildings.
\end{abstract}

Keywords CFD modeling · Building aerodynamics · Wind pressure loads · Urban street canyon $\cdot$ Verification and validation

\section{Introduction}

From the engineering applications point of view the proper information about pressure distributions is important to estimate wind pressure loads on buildings [1,2]. Owing to the fact that flow around buildings may reach considerable level of complexity, optimum building designs which avoid formation zones are important. That is why, the aim of optimum buildings designing and their location is to avoid formation zones in which the fluid acts extremely different. In view of flow complexity around buildings and presence of random vortices, there occur unsteady load on building walls. Hence it may have an impact on a safety level in the region around buildings. The pressure distributions on walls are changed due to a number of factors: geometry, an arrangement of buildings, inflow conditions and

Renata Gnatowska

gnatowska@imc.pcz.pl

1 Faculty of Mechanical Engineering and Computer Science, Czestochowa University of Technology, Al. Armii Krajowej 21, 42-200 Czestochowa, Poland 
also wind flow direction [3-6]. Blocken et al. [3] and Moryń-Kucharczyk and Gnatowska [7] analysed numerically mean flow conditions and pressures, i.e. connected with environmental issues (pedestrian-level wind, wind comfort, pollutant dispersion and ventilation). This paper has reviewed some comparative studies that systematically indicate that the lowcost wind-tunnel techniques and steady RANS simulations can provide accurate results. The region between modelled obstacles, so-called urban canopy layer, was experimentally investigated in $[4,8]$. The effect of a large group of surrounding buildings on wind pressures on a typical low-rise building have been investigated by Kim et al. [5]. These windtunnel experiments have shown that slightly different geometries of street canyon (due to differences in building shapes) can produce dramatically different flow dynamics. The pressure distributions on buildings walls can be made according to different approaches: full- and model-scale experiments and computational fluid dynamics (CFD) researches. Each approach is characterised by some benefits and disadvantages. The major benefit of the full-scale measurements is that the real conditions with the full complexity of wind environment can be analysed [9]. However, the small amount of tests is carried in a fullscale measurements due to the high costs of such research. The differences between the full- and model-scale experiments are explained in work [10]. In this research, the pressure distribution on the objects' surfaces was analysed. The results indicated that there is a high under-pressure on the building's roof. Authors in their literature review show observed notable discrepancies between the full-scale measurement results and the corresponding model test results and try to explain the causes of the problems with the traditional ABL wind tunnel simulation technique.

The advantages of wind tunnel experiments are that the parameters of boundary layer conditions can be controlled and obtained results are repeatable [11-13]. Additionally, measurements in the wind tunnel are usually carried out only for the restricted set of points [3]. On the other hand, CFD calculations provide data about complete flow area, i.e. the significant parameters in entire computational domain [3, 14-18]. An important advantage of numerical calculations is that it can be carried at the real scale (opposite are wind-tunnel experiments). Computational simulations allow for realization of researches aimed at evaluating of alternative building configurations [19]. Examples of computational calculations regarding the air flow in atmospheric boundary layer concern pedestrian-wind-level environment, wind comfort and pedestrians safety in urban areas [20-22] and natural ventilation in buildings $[1,19,23]$. In the past, CFD was applied to estimate mean pressure distributions on building walls. The most of these studies were concentrated on relatively simple shapes and surfaces $[3,24,25]$. Presented review of literature suggests that the phenomena of flow around buildings are complex, conditioned by the influence of many factors. The example result, the visualization studies of Mochida et al. [16, 26], which was carried the analysis of flow around a single object and group of obstacles, was shown in Fig. 1. However, a turbulent flow characteristic remains difficult to be described. Based on the literature review related to environmental flows, the Reynolds Averaged Navier-Stokes (RANS) modelling approaches is the most commonly used method [21, 27-33]. The choice of these methods for industrial applications, and in particular the $\mathrm{k}-\varepsilon$ family models, results from the relatively short computing time and low hardware cost.

The limitations of these models, when simulating the flow of buildings are of course known, which include over-predicting of the reattachment lengths on the roof and behind the building [34] or modelling of turbulence fields around buildings [35]. URANS (Unsteady Reynolds Averaged Naiver-Stokes) models, which enable calculation of periodical phenomena, allow for better representation of flow physics. It was shown, amongst others, by Tominaga [36] for a benchmark case of a flow around an 
Fig. 1 The flow around buildings in tandem arrangement [16]

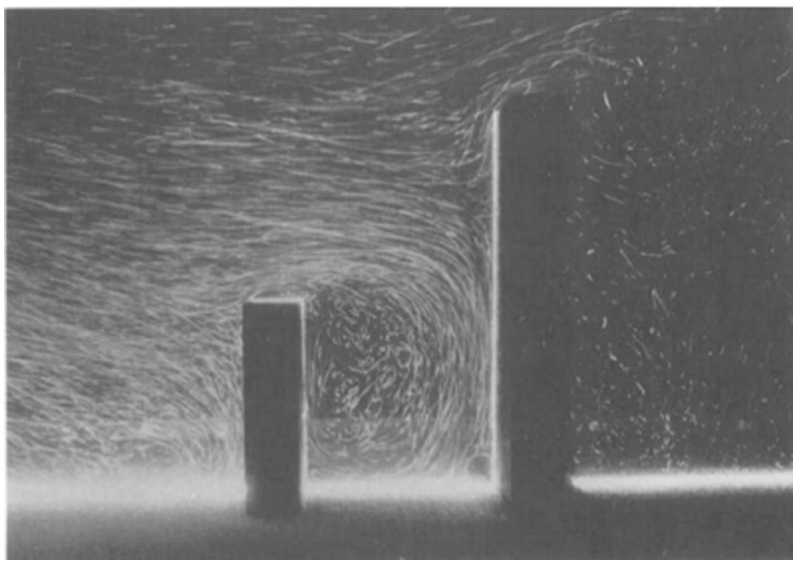

isolated building. However, even with the latter method the velocity distribution behind the building still overestimated the flow separation at the building corners. The high fidelity modelling approach, called large eddy simulation (LES), is generally believed to be capable of providing better performance than the RANS modeling approaches. However, it requires much higher expenses of computational time and resources. The performance comparisons between LES and RANS for the flow around a single building was reported by Huang et al. [37] and Tominaga et al. [32, 38]. It has been shown that LES allows for a more accurate prediction and better agreement with the experiment of the wind velocity distribution at the roof and in the wake region. However, still the uncertainty associated with this turbulence modeling approach was relatively high. Gousseau et al. [39] made a quantified validation study of the influence of inlet method and grid resolution for LES modeling of the wind flow around an isolated high rise building. It was shown that LES was more expensive than RANS in terms of finer grids and computing time requirements. So, the LES method is still considered out of reach for practical studies in actual urban environments [21]. A hybrid URANS/LES approach, called the detached eddy simulation (DES) method, was proposed to alleviate these computational problems. It was used for the analysis of the flow field in backward facing step and a configuration flat plate and the wind-induced ventilation of a building. In recent years, more studies with DES have been conducted in wind flow around blocks. Lateb et al. $[40,41]$ presented a case of pollutant dispersion from a roof top stack, and indicated that the DES results of the wind flow and dispersion fields are in better agreement with the wind tunnel experiments than RANS. Haupt et al. [42] estimated the surface pressure coefficients of a cube and showed that DES could produce high fidelity simulations at a high Reynolds number $\left(4 \times 10^{6}\right)$ flow condition. Paik et al. [43] simulated the flow pattern of two cubes by DES and the URANS and it was found that URANS failed to capture the key features of the mean flow, such as the horseshoe vortex in the upstream junction and recirculating flow on the cube top surface, especially it underestimated significant turbulence statistics in most flow regions. Nevertheless, it is expected that the increase in computing power and speed together with the intrinsically superior potential of LES and DES will render it increasingly more attractive in the years to come. But from recent studies, the RANS has a fairly high accuracy in predicting the mean flow field [14, 21, 35, 44-46], which in many cases may be sufficient. 
As it is commonly known the RANS approaches are much cheaper than LES simulations. Industry usually expects to get the results of simulations in a rather short period of time and hence, in such a case the RANS approach seems to be more preferable. For instance the study presented by Lübcke et al. [47] showed that LES is approximately 20 times more computationally expensive than RANS. This observation in also confirmed by work of Hayati et al. [48] which showed that LES approach is at least 120 times more expensive than RANS event thought the LES simulations were performed using 480 CPUs, while the RANS computations were conducted using 4 cores. In the work presented by Rodi [49] the large increase in computing time when switching from RANS to LES (even about 36 times) was also reported. Hence, it seems that the cost of LES is still too high for practical engineering computations and therefore in the present work the RANS method was adopted.

Due to the complex nature of the problem and the lack of reliable data on unsteady wind-induced pressure loads on buildings the purpose of the present paper is aimed at providing a more detailed insight into that issue. In the present work, the detailed studies in wind tunnels and analysis with numerical methods are carried out. Interaction between buildings and the flow results in increase in flow turbulence and generation of vortices in the wake behind the objects. To capture those effects the unsteady modelling method was utilised [28]. The geometry of computational domain was taken equal to the wind tunnel chamber. Therefore, this paper presents systematic and detail CFD calculations of steady and unsteady RANS for predicting pressure distributions on building walls. The aim of this research is to determine the influence of the distance between buildings in a tandem arrangement on the wind-induced pressure loads on their walls. In this paper, a fundamental study using the Reynolds-averaged Navier-Stokes (RANS and URANS method) approach of computational fluid dynamics (CFD) simulations has been carried out to study the effect of different flow angles of attack (AOA) on the wind load on buildings in tandem arrangement. Analysis was performed at $0^{\circ}, 15^{\circ}, 30^{\circ}$, and $60^{\circ}$ AOA for different distances $S / B$. The results of the present study were validated with wind-tunnel measurements realized in previous works $[50,51]$.

\section{The wind tunnel experiments}

The tunnel measurement of pressure distributions on the walls of a medium height model of building was conducted by $[50,51]$. The open-circuit wind tunnel is located in Environmental Aerodynamics Laboratory in Czestochowa University of Technology. The experimental set-up is presented in Fig. 2. The analysed configuration of building models was located within a ground boundary layer generated by the facility output from the contraction nozzle of a cross section of $400 \times 400 \mathrm{~mm}$. The test section of the wind tunnel is $4 \mathrm{~m}$ long, and the measurements were performed in the central part of the tunnel. The boundary layer was generated by a regular set of cubes on the bottom surface of the wind tunnel chamber. The vertical mean wind flow velocity profile at the position of the model of building (but without it) is represented by a power law wind velocity profile with exponent $\alpha=0.16$. Profiles of a mean and turbulent component of velocity were measured at the location of the building (but without building model present), so they present the incident flow conditions. These inflow conditions are important for CFD simulation accuracy [27]. The wind velocity measured at building height $U_{H 1}$ was equal to $7.1 \mathrm{~m} / \mathrm{s}$, and at the height of pedestrian level $U_{p p}$ was equal to $4 \mathrm{~m} / \mathrm{s}$. Figure 2 shows the relationship between 


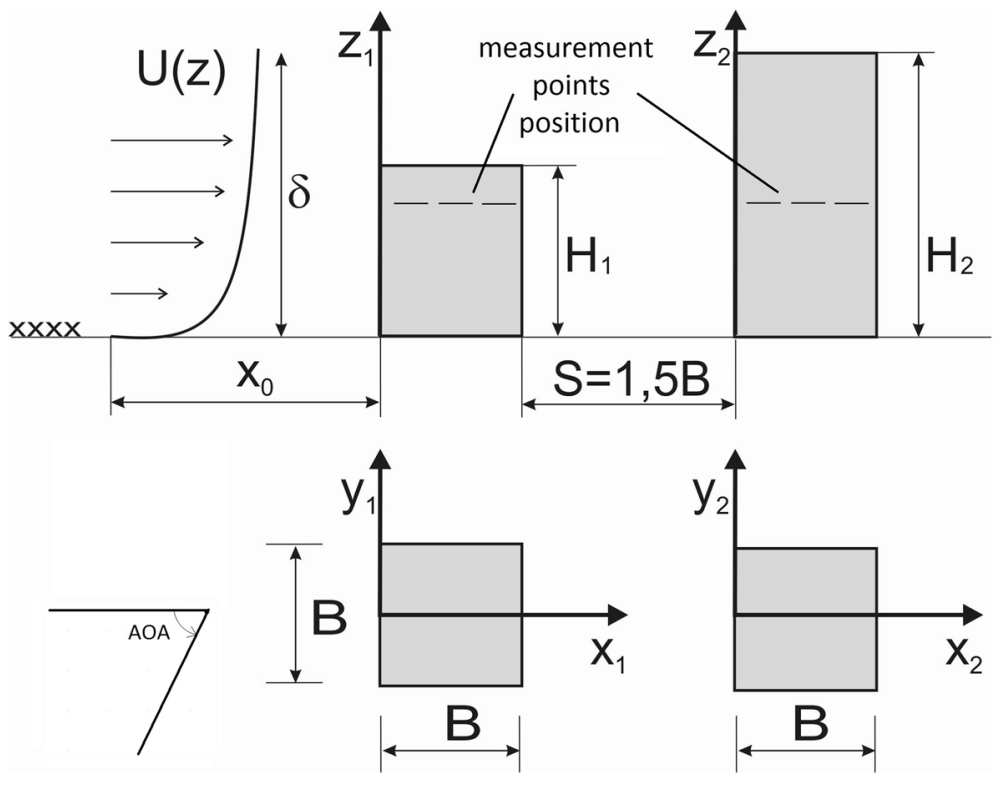

Fig. 2 Geometry of building models used in the investigation

geometrical parameters of both objects and the coordinate system used in the work. The value $S$ is the distance between the investigated elements. For whole research, the range of this parameter is changed in the range of $S / B=1.5-2.5$ with increment 0.5 . Please note that only one case $(S / B=1.5)$ was analyzed by using wind tunnel experiment. The value $B=0.04 \mathrm{~m}$ is length of objects edge, and $H_{1}$ and $H_{2}$ are the heights of buildings. The ratio of these parameters is in relationship $H_{1} / H_{2}=0.6$, and it is constant. Sizes of objects (roughness) located at the tunnel chamber bottom before the test section are $h=b=B / 6$. Total cross-section area of the object was $1.2 \%$ of calculation domain. Each research object had 9 measuring points with a diameter of $0.025 B$ These points were placed on two opposite walls, in horizontal lines placed at $0.925 H_{1}$ at each wall. The distance between the points was $0.1 B$. The pressures were measured along these lines on all facades. The measurements were performed with a pressure transducers type DCOO1NDR5 Honeywell. According to scheme in Fig. 2. The angle of attack (AOA) is the angle between the reference line perpendicular to windward wall and the incoming flow, the analysis was performed for $\mathrm{AOA}$ from $0^{\circ}$ to $60^{\circ}$.

\section{The computational simulation CFD}

The lengths and height of the computational domain were chosen based on the best practice guidelines presented in the literature $[28,52]$ and details are described also in author's article [26]. The parameters of the computational domain are: height $-6.25 H$, length $-16.7 H$ and width $-5 H$. In this study, a structured grid with $191 \times 85 \times 69$ resolution (fine grid) was used. The mesh is no uniform in each three coordinate directions. The grid is concentrated near the building model and mesh density is increased with an aspect ratio of 1.2. The first cell adjacent to the wall has been set with respect to the criteria required for the 
individual near-wall treatment. Hence, using a two-layer approach, the width of the nearwall cell has been $0.003 H_{1}$, which corresponds to $1<y+<3$, over a previously performed calculations for grid generation [26]. The detail of computational grid is shown in Fig. 3.

The ANSYS Fluent v.17.2 was used to execute the numerical calculations. Three-dimensional URANS governing equations were modelled with the RNG $\mathrm{k}-\varepsilon$ turbulence model, which was solved using the finite volume method and the SIMPLE algorithm as solution procedure. The pressure interpolation was second order and second-order discretisation schemes were used for both the convection terms and the viscous terms of the governing equations. Convergence was assumed to be obtained when all the scaled residuals levelled off and reached a minimum of $10^{-6}$ for $\mathrm{x}, \mathrm{y}$ and z-velocity, and $10^{-4}$ for k-epsilon and continuity equation [26]. The influence of the mesh density on accuracy of calculations was estimated on the basis of distribution of the longitudinal component of static pressure on the line $y / B=0.5$ (Fig. 4). Normalised time step $\Delta t^{*}=\Delta t U_{0} / B$ was chosen as 0.15 . Where $U_{0}$ is the free stream velocity and $\Delta t$ is the length of the time step estimated from the dominant frequency in the flow, representing $\approx 1 \%$ value of one period of vortex shedding [26].

A grid-sensitivity analysis with four different numbers of cells was performed. The coarse mesh $(129 \times 57 \times 55)$ is not able to capture the features of the phenomena. Increasing cells number to higher resolution $(159 \times 71 \times 56)$ provided slightly better results. Further increase in mesh resolution of hexahedral cells $(191 \times 85 \times 69)$ allowed to obtain even more accurate results. However, an even further increase in the number of cells did not lead to improvement of model accuracy. A small difference in the last stages of compaction indicates that the increase in nodes quantity does not have any influence on the calculation. So, the optimal density grid was $191 \times 85 \times 69$. The boundary condition "velocity inlet" was used to the implementation of the mean velocity profile, the turbulent kinetic energy and its dissipation energy, which were based on the measured incident vertical profiles of mean $U$ and fluctuation $u_{r m s}$ velocity components. The following boundary conditions from wind tunnel were implemented within the UDF function (User Defined Function):

- the mean velocity profile, empirical power-law,

Fig. 3 Detail of computational grid at buildings surfaces and ground surface

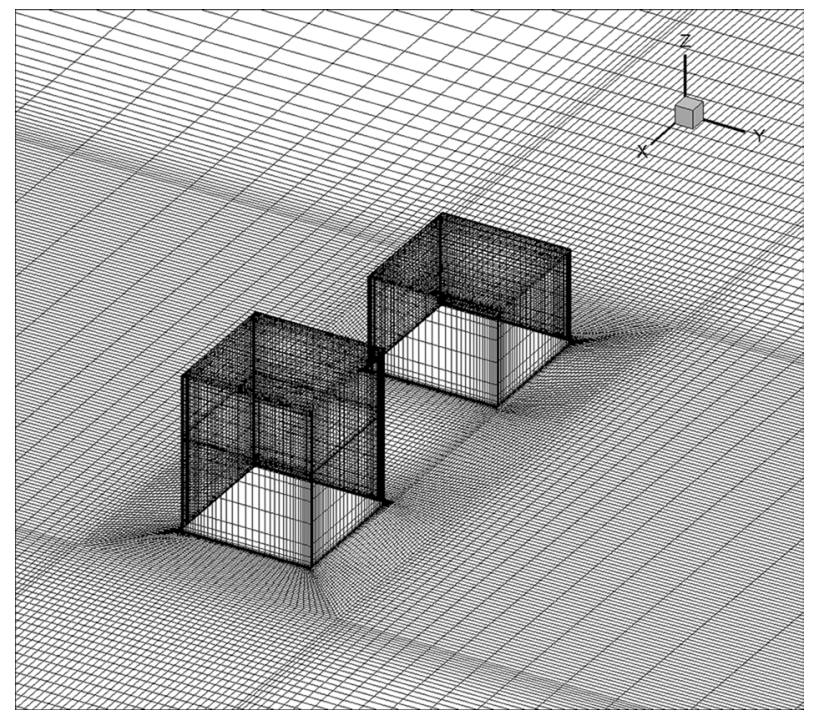


Fig. 4 Boundary conditions at the inlet

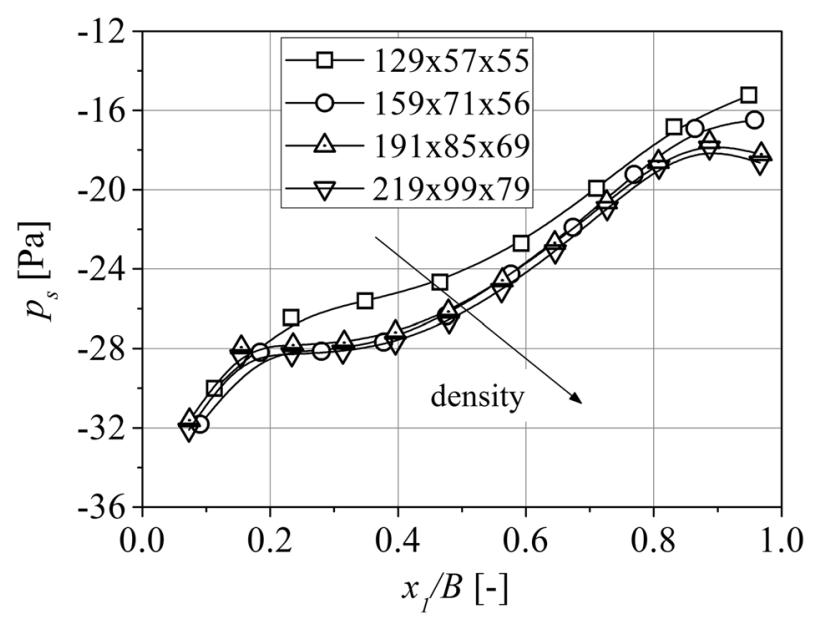

- the turbulent kinetic energy profile, derived from experimental results,

- the dissipation energy, according to equations given by [28],

$$
\varepsilon(z)=u_{*}^{3} / \kappa \cdot z
$$

where $\kappa$ is von Karman constant equals to $\kappa=0.41, \varepsilon(z)=u_{*}^{3} / \kappa \cdot z$ is friction velocity $\approx 0.04 U$.

The standard wall function by Launder and Spalding [33] is applied to the bottom surface. Condition "pressure outlet" ensures steady distribution of pressure at the outflow. At the top and lateral walls of the computational domain, the symmetry conditions were applied. They were chosen according to the recommendations compiled in the COST Action 732 after Franke et al. [27] and comply with Tominaga et al. [28]. The inlet boundary profiles are shown in Fig. 5. This illustration shows relationship between the mean wind velocity profiles measured experimentally in wind tunnel ("square" curve) and

Fig. 5 Impact of computational grid resolution on the distribution of the longitudinal component of the static pressure on line $y_{1} / B$ $=0.5$

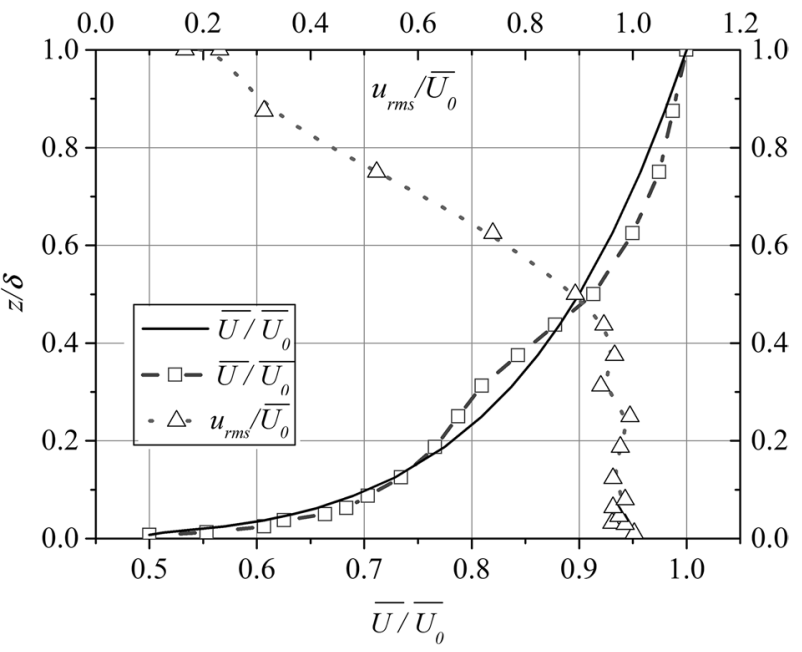


obtained empirically from power-law (black curve). In addition Fig. 5 presents the distribution of experimental fluctuation of mean velocity $\left(u_{r m s}\right)$. The fluctuation velocity can be used to calculate the turbulent kinetic energy (TKE), using formula $u_{r m s}=\sqrt{2 / 3} k$. Additional boundary conditions are:

- Inlet-power-law based on wind tunnel experiment

- Outlet-pressure outlet

- Ground and building surface — smooth wall using log-law wall function

- Top and lateral sides-symmetry boundary condition.

\section{Numerical results of pressure loads on buildings in tandem arrangement}

Pressure distribution on building walls strictly depends on the velocity distribution. When airflow acts on buildings a number of characteristic zones are created on walls and in the surrounding region what is manifested by vortices formation and local acceleration [53].

The large air masses results in strong flow circulation region in the area between buildings, which determines flow structure between them. This situation is presented in Fig. 6, which shows the result of numerical modeling of velocity field as distribution of x-component of mean velocity reduced by $U_{p p}\left(U / U_{p p}[-]\right)$. When increasing $S / B$ from 1.5 to 2.5 the impact of the windward object on the gap between buildings becomes more evident. Between the objects, the fluid flows from the top of the windward building along the leading wall of higher building and supplies local vortex, which causes acceleration in pedestrian level—see Fig. 7 (left column) presenting contours of the x-velocity component $U$ with streamlines in symmetry plane for all configurations. From both sides of buildings, fluid reaches the velocity twice as high as in the case of the flow without buildings in their location. Discussed velocity distribution has its reflection in the pressure distribution on the walls—see Fig. 7 (right column) presenting contours of the pressure coefficient $C_{p}$ defined as:

$$
c_{p}=\left(p-p_{0}\right) /\left(\frac{1}{2} \rho U^{2}\right)
$$

where $p$ is the pressure at the wall, $p_{0}$ is the reference static pressure, $\rho$ is the air density and $U$ is the reference wind velocity in undisturbed flow.

As can be seen from Fig. 7 there are higher values of $C_{p}$ on the windward wall of the first building than on the windward wall of the second one. It is caused by incoming air with undisturbed velocity field on the roofs of the both building behind the leading edge, there are under pressure zone. In those regions the air separation from the leading edges can be observed. The distance does not have any influence on the pressure distribution of the windward building because the shift of the second object doesn't cause the changes of velocity in front of the first one. Increase of distance $S / B$ causes growth in overpressure on the windward wall of the leeward object. It is caused by the smaller influence of the windward building on the velocity field of fluid incoming on the leeward object and gradual equalization of velocity field disturbed by the first object.

Figure 8 shows a comparison of the experimental pressure coefficient $C_{p}$ obtained using a HW probe, with the same numerical data on the line $\mathrm{z} / H_{1}=0.925$ on the buildings walls (windward, leeward, left and right). The analysis was conducted only for $S / B=1.5$ because for that case the measurements were made. 

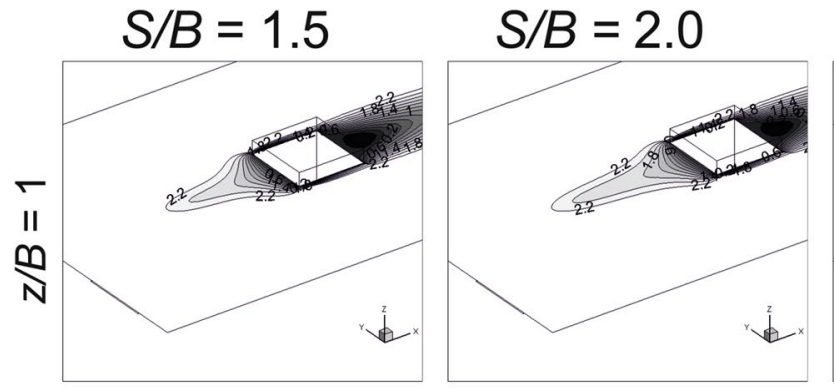

$S / B=2.5$
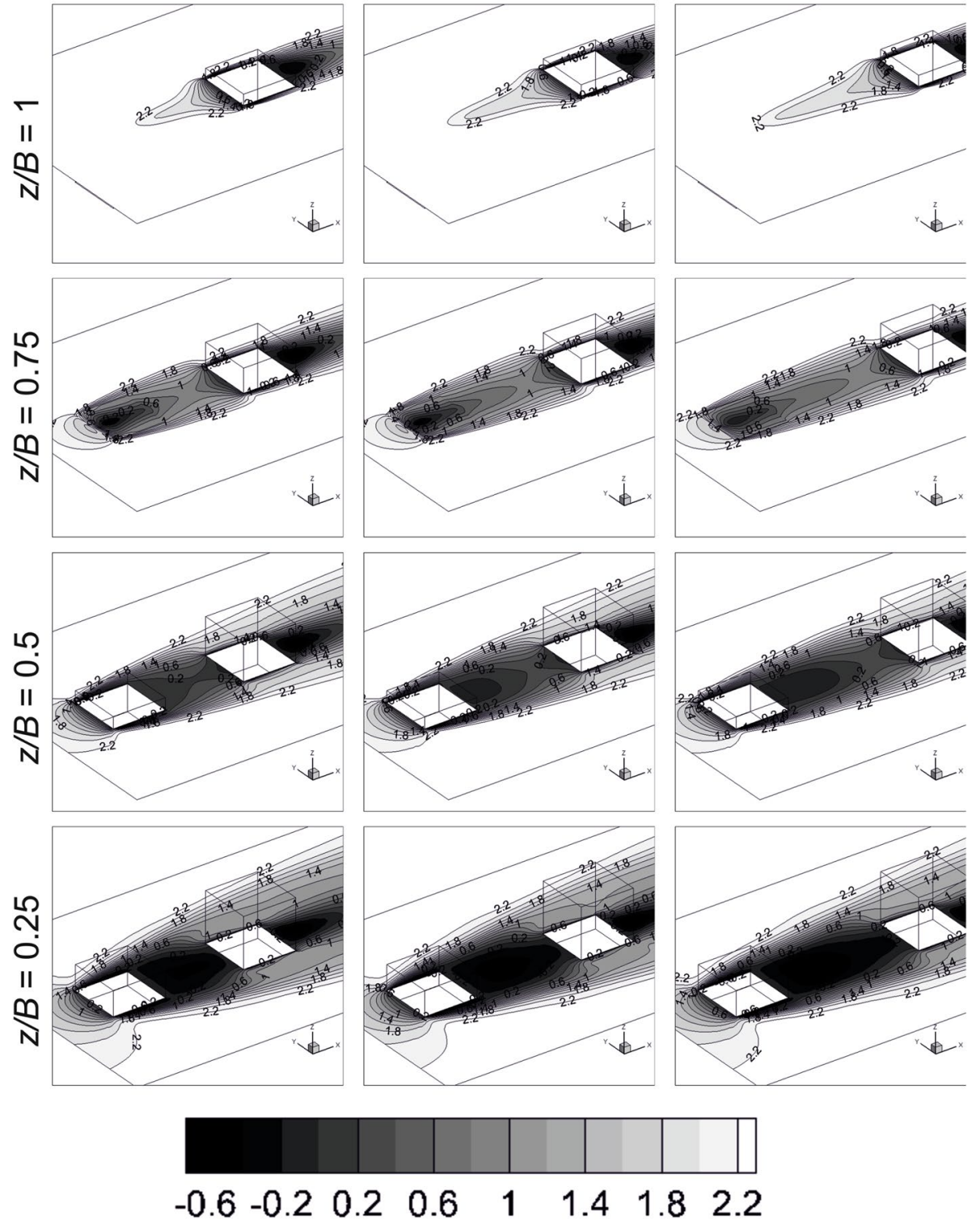

Fig. 6 The contour of normalised velocity field $U / U_{p p}[-]$ for different planes $z / B$ and distances between objects $S / B$

In general the simulation results well match the experimental data some discrepancies, however, can be observed on the side surfaces of the 1st building and on the front wall of the 2nd one. Probably the flow acceleration on the side walls of buildings' models in the wind-tunnel caused the underestimation of $C_{p}$. The discrepancies between the simulation and the experimental results on the front wall of the 2 nd object may be 

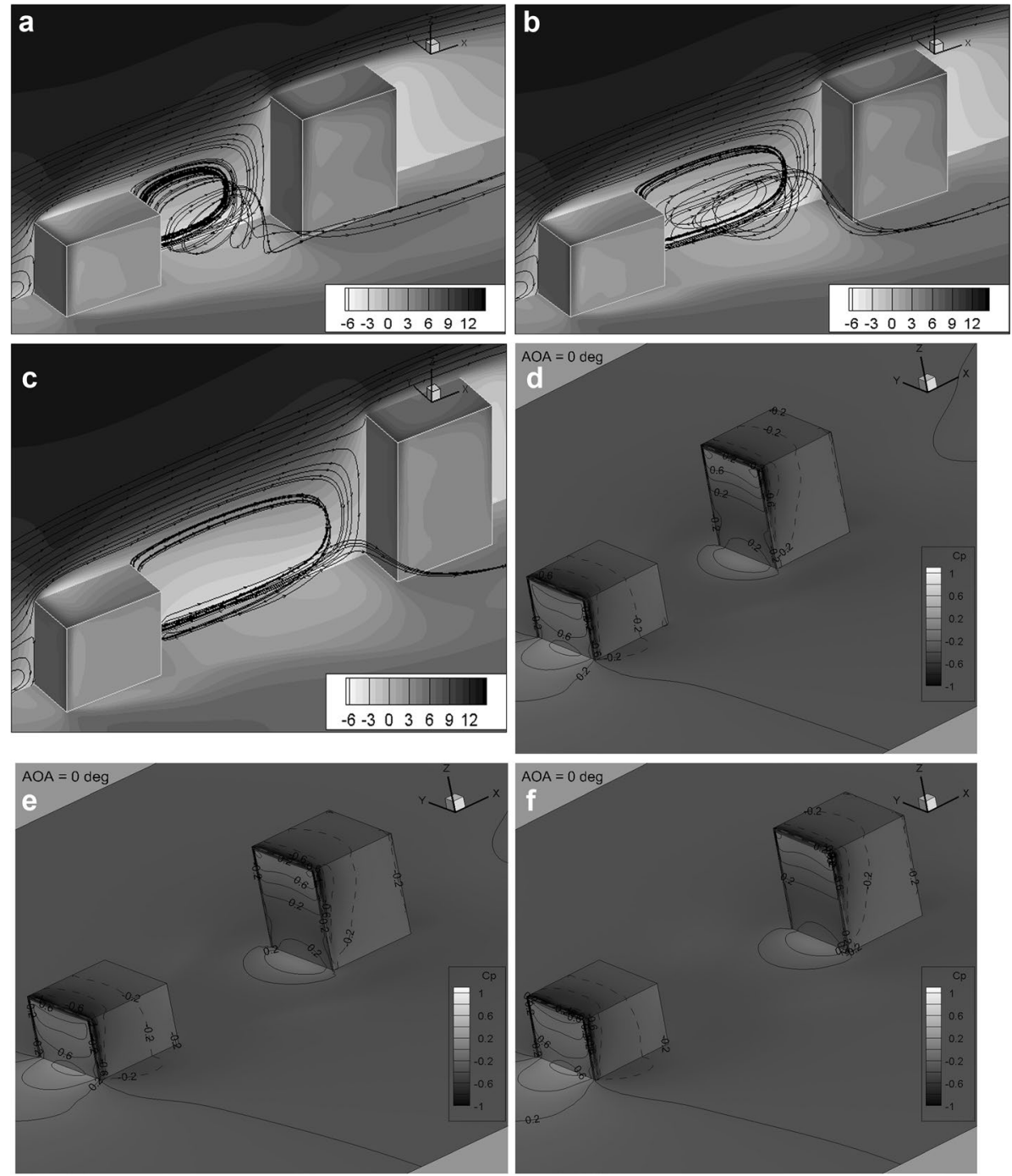

Fig. 7 Contour diagrams of the x-component mean velocity $U[\mathrm{~m} / \mathrm{s}]$ with streamlines in symmetry plane (left column) and the pressure coefficient $C_{p}[-]$ (right column) obtained by CFD simulation (time averaged) for distances between objects arranged in tandem: a, d $S / B=1.5 ; \mathbf{b}, \mathbf{e} S / B=2.0 ; \mathbf{c}, \mathbf{f} S / B=2.5$

caused due to the presence of recirculation region in the gap between prisms where the flow is unstable. Despite these discrepancies one may ascertain that the RANS model is sufficient enough to predict the flow behaviour in the given objects' configuration. Worthy of note is negative value of $C_{p}$ on the leeward wall of the 1 st object $\left(C_{p} \approx-0.22\right.$ across the width of the object). On the windward wall of second object $C_{p}$ is positive what means that there is an overpressure (higher on the front wall of the front building than on the front wall of the 2 nd building). This is due to the 2 nd object is immersed in the aerodynamic wake of the 1 st one. For the leeward surface of the second object the pressure distribution is constant (approximately $C_{p} \approx-0.18$ ). For the side walls of the 
a

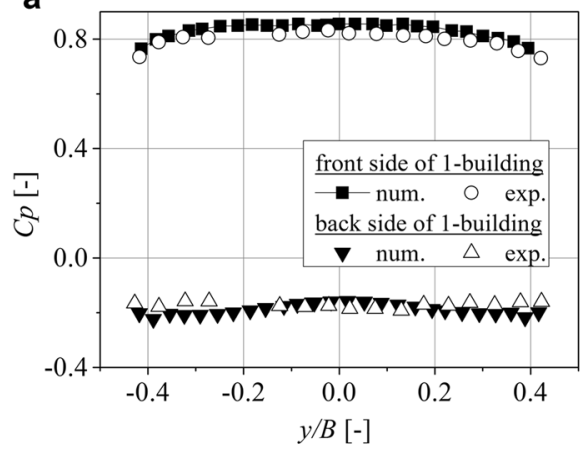

C

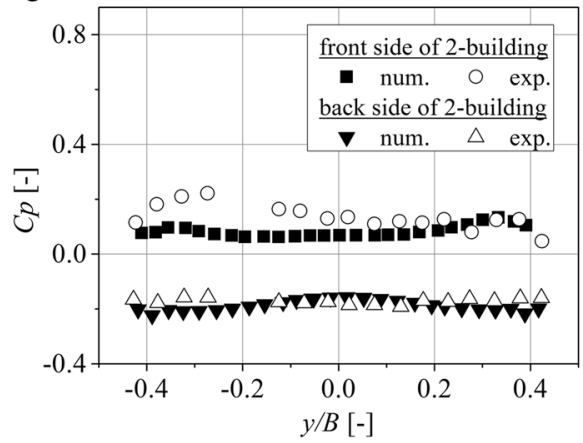

b

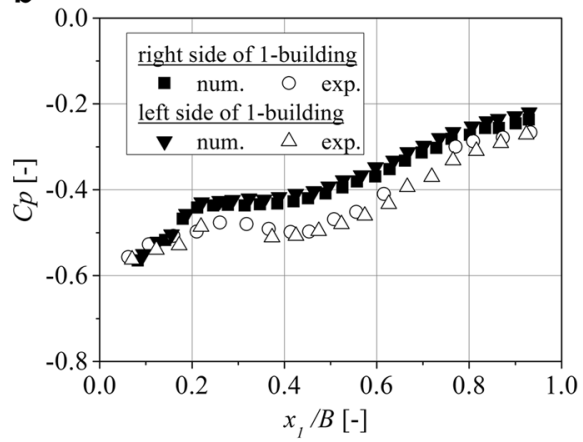

d

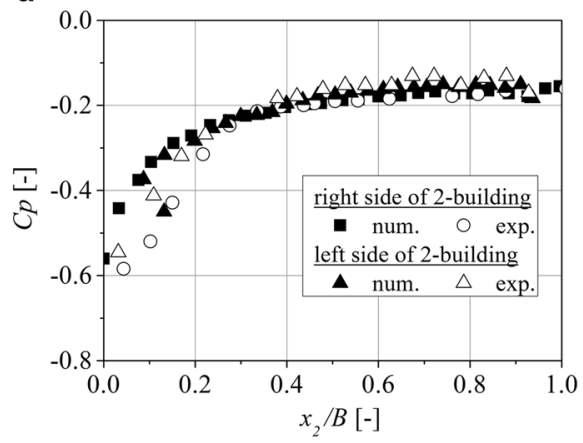

Fig. 8 Comparison of pressure coefficient $\left(C_{p}[-]\right)$, for parameter $S / B=1.5$, obtained by CFD simulation (time averaged) results and wind-tunnel experiments along measuring line on a windward and leeward walls of 1-building; $\mathbf{b}$ side walls of 1-building; $\mathbf{c}$ windward and leeward walls of 2-building; $\mathbf{d}$ side walls of 2-building

1st building the gradual increase of pressure was observed, from the value $C_{p}-0.6$ to - 0.3 For the opposite wall the distribution of $C_{p}$ was symmetrical-in CFD calculations and wind tunnel experiment.

Even more interesting is when the flow field changes are observed in time. To do so the unsteady RANS (URANS) simulations were conducted. The impact of velocity fluctuations on changing the building load is noticeable. To analyse variation of pressure range, $C_{p}$ for subsequent moments were set, for successive moments of time for $\Delta t=T / 4$, where $T$ is the oscillation period of the velocity field. The impact of velocity fluctuations on changing the building load is noticeable. Wake created behind the 1st building, in which the oscillation changes of velocity occur, results in the change of $C_{p}$ on the front wall of the second building.

Due to the complex nature of the problem and lack of reliable data or analytical procedures for predicting the wind load effect it seems reasonable to extend the result section with additional data obtained for different wind directions. The significance of this parameter is evidenced, for example, by the results obtained by Yamartino and Wiegand [54], who stated that the angle of attack (AOA) was found to influence the formation of a mean recirculating flow in the street canyon. In order to analyse the influence of AOA on the pressure load of the building, additional numerical calculations were carried out for the selected configuration of objects with the distance between objects $S / B=1.5$ and for 


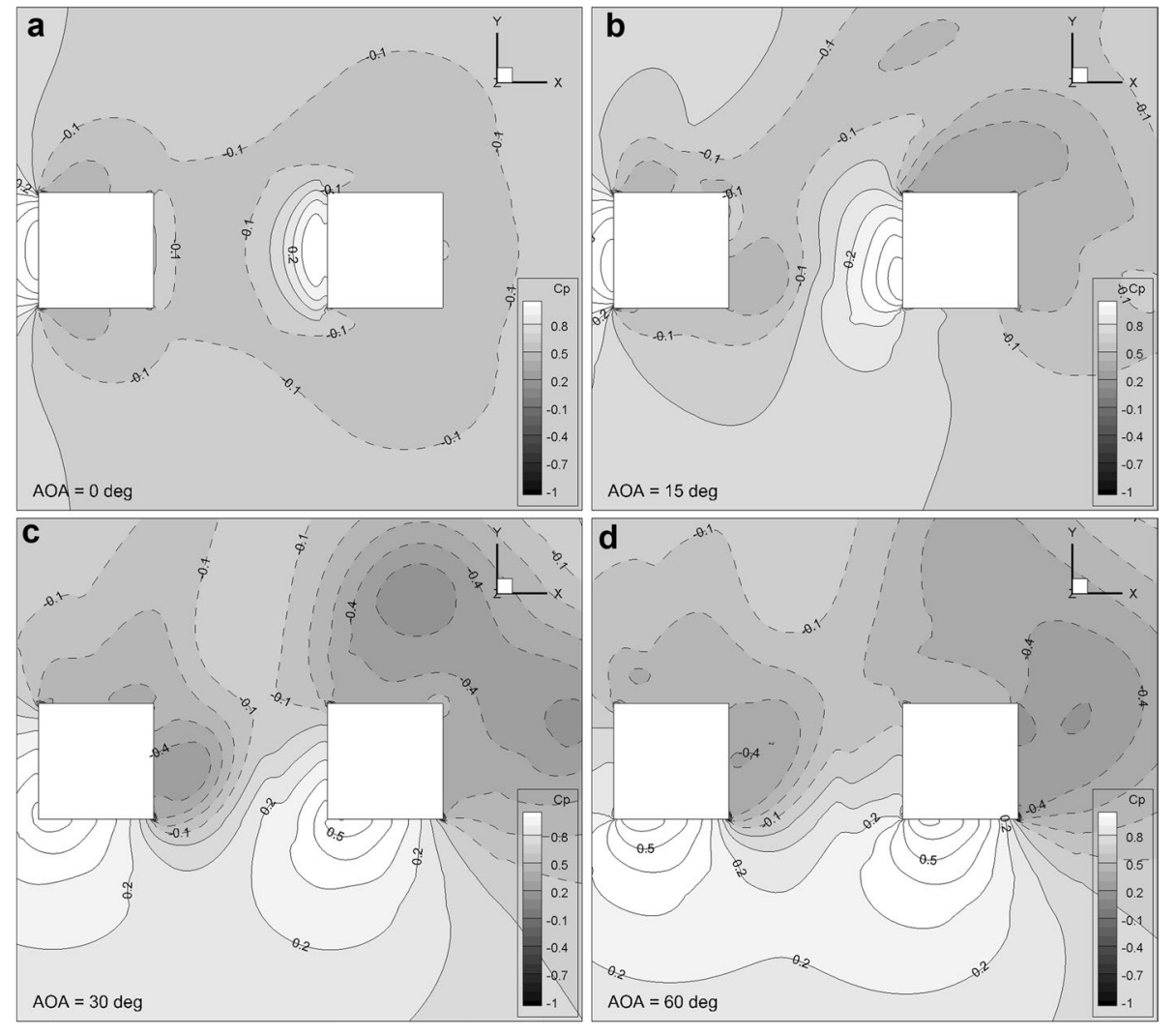

Fig. 9 Top view on pressure distribution at ground level between buildings in tandem arrangement for distance between them $S / B=1.5$ for different inflow wind direction a $\mathrm{AOA}=0 \mathrm{deg} ; \mathbf{b} \mathrm{AOA}=15 \mathrm{deg}$; $\mathbf{c} \mathrm{AOA}$ $=30 \mathrm{deg} ; \mathbf{d} \mathrm{AOA}=60 \mathrm{deg}$

the three flow angels of attack changing from $15^{\circ}$ to $60^{\circ}$. Figure 9 presents top view on pressure distribution at ground level between buildings for consecutive cases. A contour presented in this figure indicates that wind-induced pressure loads vary significantly with changing wind direction.

For $\mathrm{AOA}=0^{\circ}$ (Fig. 9a) the isolines of constant $C p$ are distributed uniformly on both side of buildings arrangement), as expected. Further, the figures from Fig. $9 \mathrm{~b}$ to $9 \mathrm{~d}$ reveal that the flow structure in the surrounding of objects loses symmetry for flow angles different from $0^{\circ}$ AOA. As can be seen, already an increase in AOA from $0^{\circ}$ to $15^{\circ}$ is sufficient for the downstream object to be released from the aerodynamic wake produced by the upstream one what is manifested by presence of positive $C_{p}$ values (solid lines) in the closest vicinity of the side wall of the second building. When AOA reaches $30^{\circ}$ the negative values of $C_{p}$ (dashed lines) appear near the upstream wall of second building but closer to the left corner. Increasing in AOA to $60^{\circ}$ causes a shift of the negative $C_{p}$ towards the right corner of the upstream wall of the second building. In this case the negative $C_{p}$ is also observed in the region of near the upstream wall of the first building, however closer to the left corner. The further increase in AOA would lead to the situation when both objects are located side by side with respect to the flow, and such situation well were described in number of previous works [55-57]. It can be concluded that the flow 


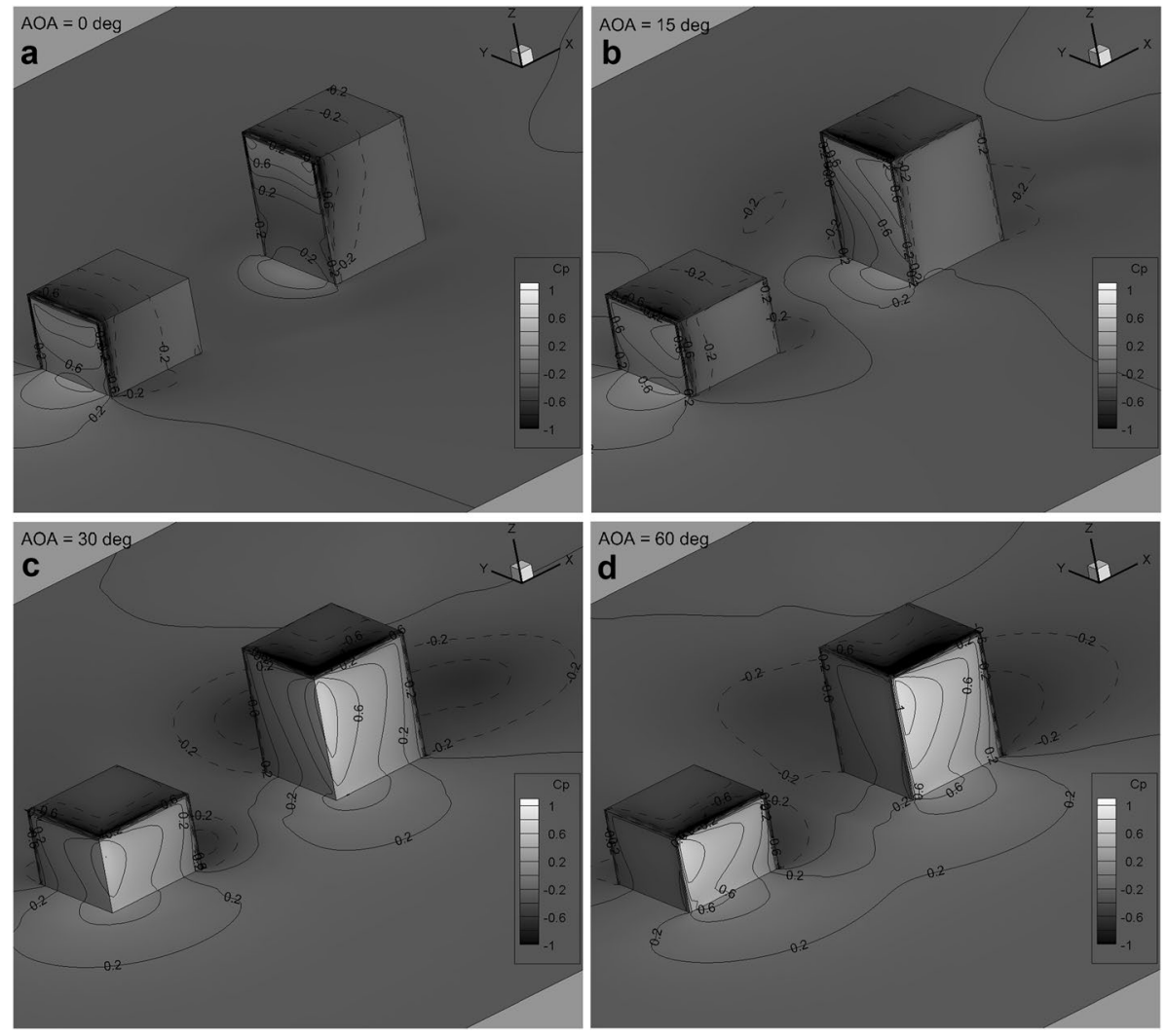

Fig. 10 The 3D view on pressure coefficient $C_{p}[-]$ distribution at ground level between buildings in tandem arrangement for distance between them $S / B=1.5$ for different inflow wind direction $\mathbf{a} \mathrm{AOA}=0 \mathrm{deg} ; \mathbf{b}$ $\mathrm{AOA}=15 \mathrm{deg} ; \mathbf{c} \mathrm{AOA}=30 \mathrm{deg} ; \mathbf{d} \mathrm{AOA}=60 \mathrm{deg}$

pattern varies drastically as the angle of inflow increase, which must consequently affect the pressure loads of objects. This is seen in Fig. 10, which presents 3D view of pressure coefficient $C_{p}$ distribution on buildings with increasing AOA for $S / B=1.5$. For $\mathrm{AOA}=0^{\circ}$ (Fig. 10a) the isolines of constant $C_{p}$ on building surfaces are distributed symmetrically and characteristic regions like separation regions on windward walls and separation of the flow on the edge of the building roof and recirculation and reattachment of the flow in the wake of the buildings are visible. Such a structure of flow and pressure distribution are mainly due to combination of interference between objects and downwash effect of wind [30]. The increase AOA to $15^{\circ}$ caused a deviation of the $C_{p}$ contours from the symmetry towards the inflow side (the right corner of the upstream walls of both buildings). When AOA reaches $30^{\circ}$, the pressure is distributed almost uniformly on both walls sharing the right upstream edge (for both buildings). For inflow angle $\mathrm{AOA}=60^{\circ}$ the opposite situation occurs, namely, the higher pressure acts on the side instead of front walls. The analysis shows that the inflow angle has a significant impact on the local loading on the buildings walls, which, in particular with a short distance between them, results from the deviation of the wake of the upstream building and weakening of the downwash effect.

Figure 11 shows the instantaneous distribution of mean wind pressure coefficient $C_{p}[-]$ on objects' walls and ground level for different distances between buildings and different 


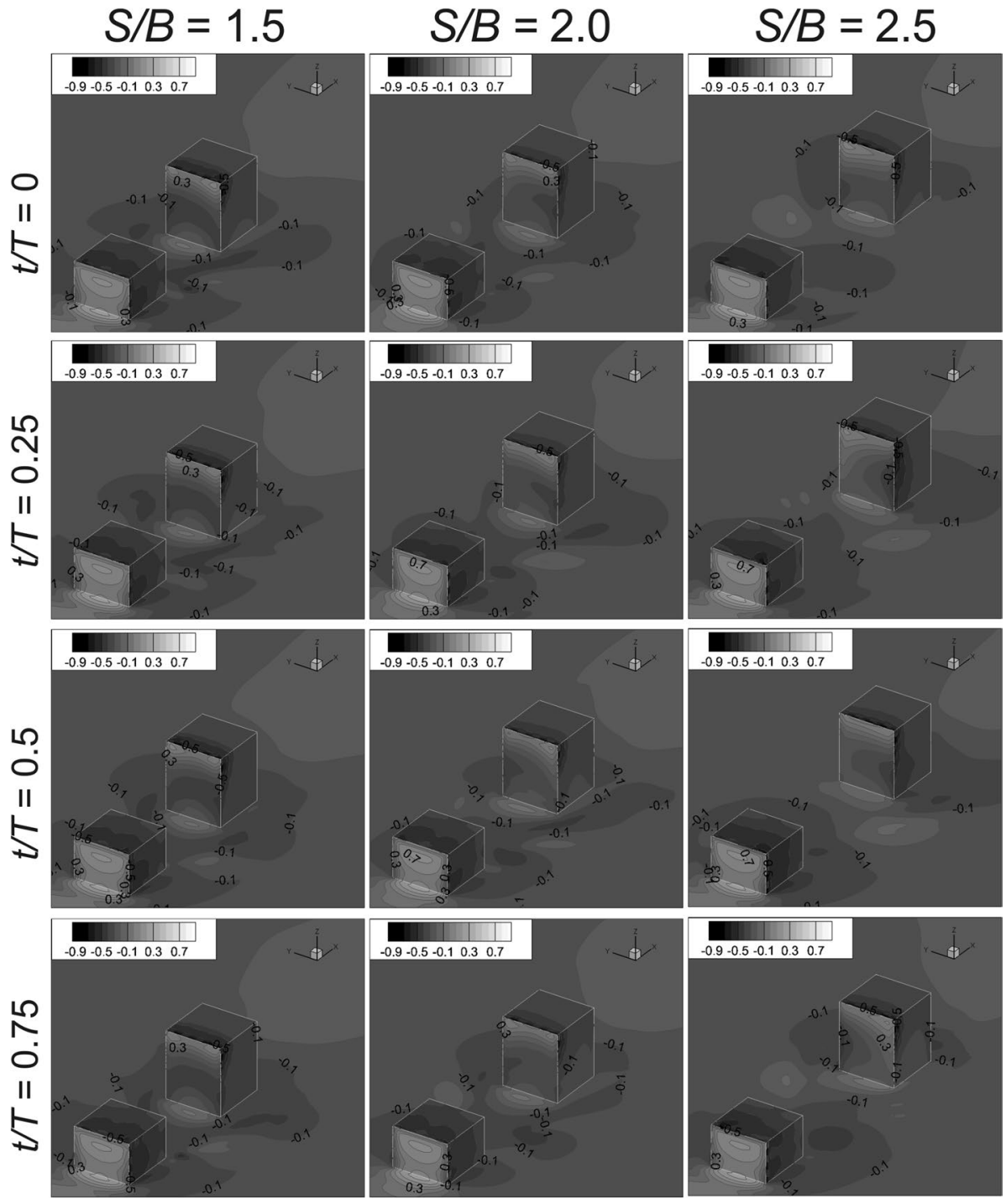

Fig. 11 Time evolution of the pressure coefficient $C_{p}[-]$ distribution on objects walls and ground level for different distances between objects arranged in tandem: in range from $S / B=1.5$ to $S / B=2.5$

moments in normalised time $t / T$ (where $T$ is the oscillation period of the velocity field). The most remarkable wind-induced pressure loads on buildings were observed on the windward wall of the second object. With increasing $S / B$ variation in $C_{p}$ is more pronounced.

The biggest changes concern especially the windward wall of the 2 nd building. As a results of observation time pressure changes for configuration $S / B=1.5$ in time $t / T=0$, the area of overpressure on the windward wall in 2 nd building is not symmetric and takes larger area on the one side of object. In the next time step $(t / T=0.25)$ the pressure distribution in that part is first stable and then in time $t / T=0.5$ occupies larger area on the other side. Similar situation takes place as a result of objects distancing, but fluctuations on the 
windward wall are visible. For the configuration of $S / B=2.5$ and $t / T=0$ the under-pressure affects one side of building, later its distribution is symmetric, and then it "moves" to the opposite part. The pressure change takes place only for element being in wake. Fluctuations do not apply to windward building, what is connected with unaffected flow structure acting on it. For that object, the varying nature of flow in the time does not cause variation in pressure range for all configurations.

The most significant changes are observed at the height under $H_{1}$. Figure 12, presents the instantaneous distribution of mean wind pressure coefficient $C_{p}[-]$ at objects' walls and at the plane $\mathrm{z} / \mathrm{H}_{1}=0.925$.

This figure includes analysis of the pressure distribution in the area around the building (i.e. not at the building facade). Moreover, these results confirmed that fluctuations of an incoming wind play an important role in determining wind pressure distributions around buildings. For better interpretation of previous observations Fig. 13 shows the variation

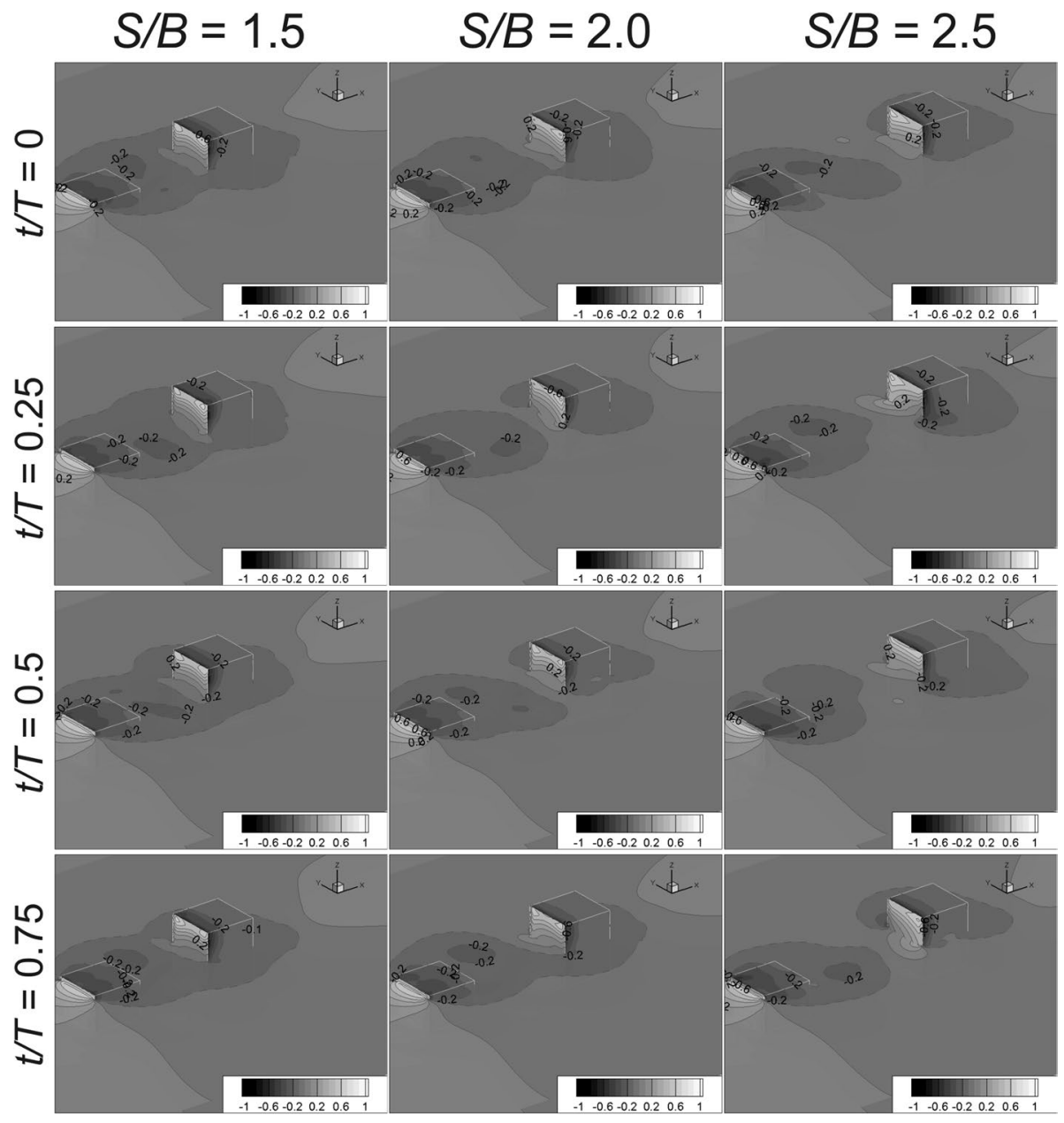

Fig. 12 Time evolution of the pressure coefficient $C_{p}[-]$ distribution at the plane $z / H_{1}=0.925$ and on objects walls for different distances between objects arranged in tandem in range from $S / B=1.5$ to $S / B=$ 2.5 

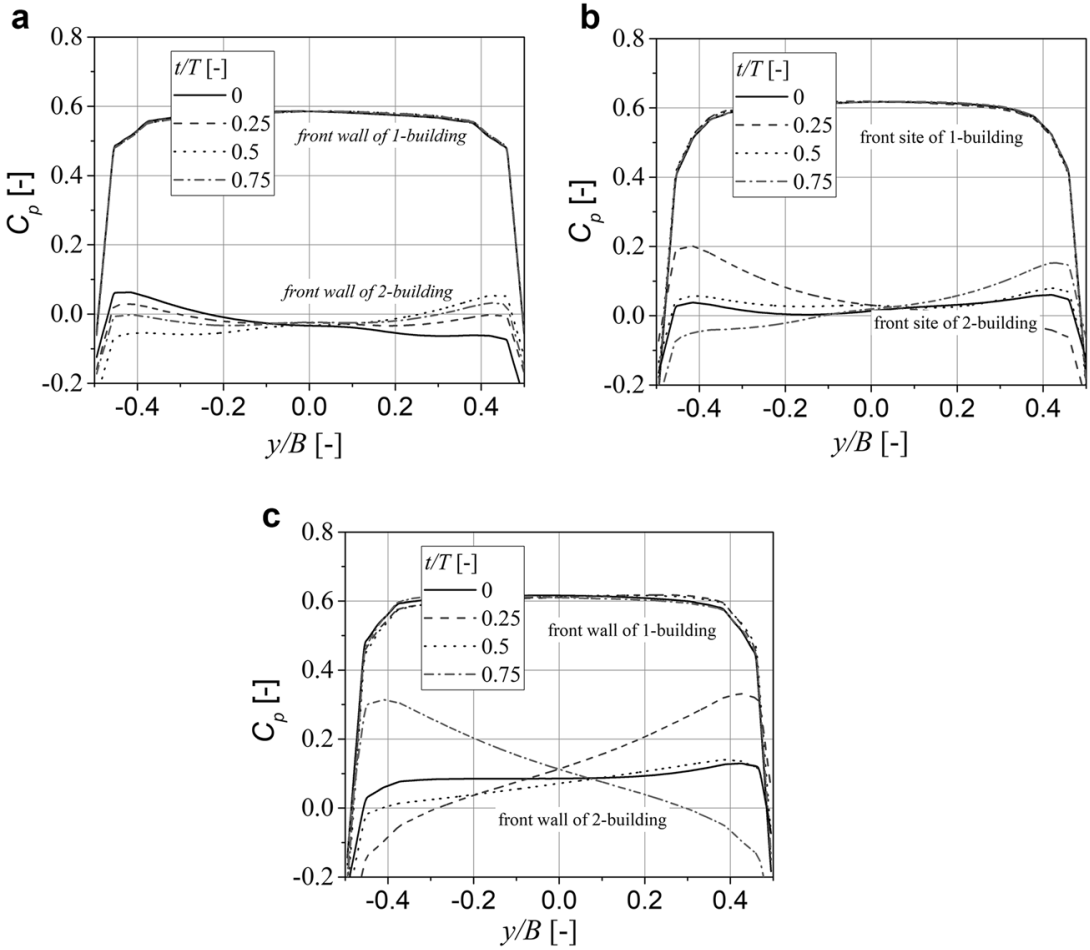

Fig. 13 Time-evolution of surface pressure coefficient $\mathrm{Cp}[-]$ on the front site of the windward and leeward buildings at the line $\mathrm{z} / \mathrm{H}=0.925$ for configurations: $\mathbf{a} \mathrm{S} / \mathrm{B}=1.5 ; \mathbf{b} \mathrm{S} / \mathrm{B}=2.0 ; \mathbf{c} \mathrm{S} / \mathrm{B}=2.5$

of the pressure coefficient $C_{p}$ at line $\mathrm{z} / H_{1}=0.925$ different spacing $S / B$. As can be seen the variation of $C_{p}$ increases with increasing spacing $S / B$ and the most evident changes in $C_{p}$ can be observed near the corners of the windward wall of the second object. Similar flow behaviour with changing $S / B$ was observed in the previous works $[53,58]$. Worthy mentioning is also that the pressure loads changes on the windward wall of the first object, are negligible.

The study of unsteady flow shows, that the changeable pressure load has influence on the 2 nd object. It causes the necessity to analyse the load structure during the building design. It can be assume that these high loads are due to the dynamic response of the separating and reattaching flow which periodically rolls up into the vortex.

\section{Conclusions}

This article presents systematic studies showing the assessment of steady and unsteady 3D RANS calculations for forecasting the distribution of wind loads caused by airflow around buildings in tandem arrangement. The numerical model was validated against experimental data from wind tunnel and grid independence tests were conducted to minimise the numerical error. In the range of work there is also determination of the distance influence between objects on the pressure distribution on buildings' walls. 
The wind-induced load is a very complex problem. The angle of attack as well as neighbouring buildings may increase or decrease wind loads depending on their relative location. The analysis of the latter factor showed that increasing the distance between elements has the positive influence on the mean pressure values on the front wall the of the second building, while unsteady analysis of the flow showed, however that the increase in distance intensifies the periodic pressure fluctuation of loads affecting the 2 nd building due to the vortex shedding behind the 1st building. It was found that it is the unfavourable situation from the viewpoint of the impact on the building construction because fluctuations of load can have special meaning for the material fatigue and can cause vibration of the buildings.

In order to analyse the influence of AOA on the pressure load of the building, additional numerical calculations were carried out for the selected configuration of objects with the distance between objects $S / B=1.5$. It was shown that flow pattern varies drastically as the angle of inflow increase, which must consequently affect the pressure distributions and wind-induced pressure loads of objects. The results reveal that the flow structure in the surrounding of objects gradually loses symmetry for flow angles different from $0^{\circ}$ AOA. The analysis shows that this situation is caused in particular with a short distance between buildings, the deviation of the aerodynamic wake of the upstream building and weakening of the downwash effect.

The earlier researchers usually focused on the buildings responses due to interference effects. From the present study, it has been observed that the most significant interference effects depend on wind direction flow and relative distance between buildings. Upstream building has induced shielding effects to reveal decreasing the mean wind load on the downstream building. The results obtained from this study will be helpful to the building designer or city planner to predict the effect of wind load on structures. There is the lack of data important for estimation of pedestrian wind comfort for complicated building configurations, in particular, related to the understanding of the possible wind problems in cities. During the realization of the work, the rightness of using numerical tools was confirmed in engineering solutions and huge potential was shown if it comes to ease of gaining the data needed to analysis.

More simulations are need to be carried out and further investigations are required to obtain information about the optimum separation of buildings that will allow avoiding the dangerous wind loads and destructive resonance phenomenon. It is important to analyse the influence of flow disorders and its periodic fluctuation on the dynamic response of construction.

Acknowledgements The work was partially supported by National Science Centre, Poland (Narodowe Centrum Nauki) under Grant No. NCN 2017/01/X/ST8/00076. This research was supported in part by PLGrid Infrastructure.

Open Access This article is distributed under the terms of the Creative Commons Attribution 4.0 International License (http://creativecommons.org/licenses/by/4.0/), which permits unrestricted use, distribution, and reproduction in any medium, provided you give appropriate credit to the original author(s) and the source, provide a link to the Creative Commons license, and indicate if changes were made.

\section{References}

1. Kuznetsov S, Butova A, Pospíšil S (2016) Influence of placement and height of high-rise buildings on wind pressure distribution and natural ventilation of low- and medium-rise buildings. Int $\mathrm{J}$ Vent 15:253-266. https://doi.org/10.1080/14733315.2016.1214396 
2. Sanquer S, Caniot G (2015) Wind-induced pressure coefficients on buildings dedicated to air change rate assessment with CFD tool in complex urban areas. In: Proceedings of the 36th AIVC-5th TightVent-3rd venticool conference, pp 23-24

3. Blocken B, Stathopoulos T, van Beeck JPAJ (2016) Pedestrian-level wind conditions around buildings: review of wind-tunnel and CFD techniques and their accuracy for wind comfort assessment. Build Environ 100:50-81. https://doi.org/10.1016/j.buildenv.2016.02.004

4. Kellnerová R, Kukačka L, Jurčáková K et al (2012) PIV measurement of turbulent flow within a street canyon: detection of coherent motion. J Wind Eng Ind Aerodyn 104-106:302-313. https://doi. org/10.1016/j.jweia.2012.02.017

5. Kim YC, Yoshida A, Tamura Y (2012) Characteristics of surface wind pressures on low-rise building located among large group of surrounding buildings. Eng Struct 35:18-28. https://doi.org/10.1016/j. engstruct.2011.10.024

6. Gnatowska R (2008) Synchronization phenomena in systems of bluff-bodies. Int J Turbo Jet Engines 25:121-128

7. Moryń-Kucharczyk E, Gnatowska R (2007) Pollutant dispersion in flow around bluff-bodies arrangement. In: Schaumann P, Barth S, Peinke J (eds) Wind energy. Proceedings of the Euromech Colloquium. Wind energy. Springer, Berlin

8. Gnatowska R, Sosnowski M, Uruba V (2017) CFD modelling and PIV experimental validation of flow fields in urban environments. In: E3S web of conferences. EDP Sciences, p 1034

9. Richards PJ, Hoxey RP (2012) Pressures on a cubic building-part 1: full-scale results. J Wind Eng Ind Aerodyn 102:72-86. https://doi.org/10.1016/j.jweia.2011.11.004

10. Cheng XX, Dong J, Peng Y et al (2017) Full-scale/model test comparisons to validate the traditional ABL wind tunnel simulation technique: a literature review. https://doi.org/10.20944/prepr ints201710.0046.v1

11. Richards PJ, Hoxey RP, Connell BD, Lander DP (2007) Wind-tunnel modelling of the Silsoe Cube. J Wind Eng Ind Aerodyn 95:1384-1399. https://doi.org/10.1016/j.jweia.2007.02.005

12. Montazeri H, Blocken B (2013) CFD simulation of wind-induced pressure coefficients on buildings with and without balconies: validation and sensitivity analysis. Build Environ 60:137-149. https:// doi.org/10.1016/j.buildenv.2012.11.012

13. Bady M, Kato S, Takahashi T, Huang H (2011) Experimental investigations of the indoor natural ventilation for different building configurations and incidences. Build Environ 46:65-74. https:// doi.org/10.1016/j.buildenv.2010.07.001

14. Blocken B, Janssen WD, van Hooff T (2012) CFD simulation for pedestrian wind comfort and wind safety in urban areas: general decision framework and case study for the Eindhoven University campus. Environ Model Softw 30:15-34. https://doi.org/10.1016/j.envsoft.2011.11.009

15. Baetke F, Werner H, Wengle H (1990) Numerical simulation of turbulent flow over surfacemounted obstacles with sharp edges and corners. J Wind Eng Ind Aerodyn 35:129-147. https://doi. org/10.1016/0167-6105(90)90213-V

16. Murakami S, Mochida A, Hayashi Y, Hibi K (1990) Numerical simulation of velocity field and diffusion field in an urban area. Energy Build 15:345-356. https://doi.org/10.1016/03787788(90)90008-7

17. Nore K, Blocken B, Thue JV (2010) On CFD simulation of wind-induced airflow in narrow ventilated facade cavities: coupled and decoupled simulations and modelling limitations. Build Environ 45:1834-1846. https://doi.org/10.1016/j.buildenv.2010.02.014

18. Ahmad S, Muzzammil M, Zaheer I (2011) Numerical prediction of wind loads on low buildings. Int J Eng Sci Technol 3:59-72. https://doi.org/10.4314/ijest.v3i5.68567

19. van Hooff T, Blocken B, Aanen L, Bronsema B (2011) A venturi-shaped roof for wind-induced natural ventilation of buildings: wind tunnel and CFD evaluation of different design configurations. Build Environ 46:1797-1807. https://doi.org/10.1016/j.buildenv.2011.02.009

20. Blocken BÃ, Persoon J (2009) Pedestrian wind comfort around a large football stadium in an urban environment: CFD simulation, validation and application of the new Dutch wind nuisance standard. J Wind Eng Ind Aerodyn 97:255-270. https://doi.org/10.1016/j.jweia.2009.06.007

21. Yoshie R, Mochida A, Tominaga Y, Kataoka H (2007) Cooperative project for CFD prediction of pedestrian wind environment in the Architectural Institute of Japan. J Wind Eng Ind Aerodyn 95:1551-1578. https://doi.org/10.1016/j.jweia.2007.02.023

22. Toja-silva F, Peralta C, Lopez-garcia O et al (2015) Roof region dependent wind potential assessment with different RANS turbulence models. J Wind Eng Ind Aerodyn 142:258-271. https://doi. org/10.1016/j.jweia.2015.04.012 
23. Ramponi R, Blocken B (2012) CFD simulation of cross-ventilation for a generic isolated building: impact of computational parameters. Build Environ 53:34-48. https://doi.org/10.1016/j.build env.2012.01.004

24. Dagnew AK, Bitsuamlak GT (2013) Computational evaluation of wind loads on buildings: a review. Wind Struct Int J 16:629-660. https://doi.org/10.12989/was.2013.16.6.629

25. Blocken B (2015) Computational fluid dynamics for urban physics: importance, scales, possibilities, limitations and ten tips and tricks towards accurate and reliable simulations. Build Environ 91:219-245. https://doi.org/10.1016/j.buildenv.2015.02.015

26. Gnatowska R (2018) Effect of inlet conditions for numerical modelling of the urban boundary layer. In: AIP conference proceedings, p 110008. https://doi.org/10.1063/1.5019111

27. Franke J, Hellsten A, Schlünzen H, Carissimo B (2010) The Best Practise Guideline for the CFD simulation of flows in the urban environment: an outcome of COST 732. In: The fifth international symposium on computational wind engineering, pp 1-10

28. Tominaga Y, Mochida A, Yoshie R (2008) AIJ guidelines for practical applications of CFD to pedestrian wind environment around buildings. J Wind Eng Ind Aerodyn 96:1749-1761. https://doi. org/10.1016/j.jweia.2008.02.058

29. Tominaga Y, Stathopoulos T (2017) Steady and unsteady RANS simulations of pollutant dispersion around isolated cubical buildings: effect of large-scale fluctuations on the concentration field. J Wind Eng Ind Aerodyn 165:23-33. https://doi.org/10.1016/j.jweia.2017.02.001

30. Tominaga Y, Stathopoulos T (2013) CFD simulation of near-field pollutant dispersion in the urban environment: a review of current modeling techniques. Atmos Environ 79:716-730. https://doi. org/10.1016/j.atmosenv.2013.07.028

31. Shih T-H, Liou WW, Shabbir A et al (1995) A new k- $\varepsilon$ eddy viscosity model for high :reynolds number turbulent flows. Comput Fluids 24:227-238. https://doi.org/10.1016/0045-7930(94)00032-T

32. Tominaga Y, Mochida A, Murakami S, Sawaki S (2008) Comparison of various revised k- $\varepsilon$ models and LES applied to flow around a high-rise building model with 1:1:2 shape placed within the surface boundary layer. J Wind Eng Ind Aerodyn 96:389-411. https://doi.org/10.1016/j.jweia.2008.01.004

33. Launder BE, Spalding DB (1974) The numerical computation of turbulent flows Van Driest's constant Curte t number defined by (3. 1-1). Coefficients in approximated turbulent transport equations. Specific heat at constant pressure. Diffusion coefficient for quantity. p Rate of Diffus 3:269-289

34. Mochida A, Lun IYF (2008) Prediction of wind environment and thermal comfort at pedestrian level in urban area. J Wind Eng Ind Aerodyn 96:1498-1527. https://doi.org/10.1016/j.jweia.2008.02.033

35. Blocken B (2014) 50 years of computational wind engineering: past, present and future. J Wind Eng Ind Aerodyn 129:69-102. https://doi.org/10.1016/j.jweia.2014.03.008

36. Tominaga Y (2015) Flow around a high-rise building using steady and unsteady RANS CFD: effect of large-scale fluctuations on the velocity statistics. J Wind Eng Ind Aerodyn 142:93-103. https://doi. org/10.1016/j.jweia.2015.03.013

37. Huang S, Li QS, Xu S (2007) Numerical evaluation of wind effects on a tall steel building by CFD. J Constr Steel Res 63:612-627. https://doi.org/10.1016/j.jcsr.2006.06.033

38. Tominaga Y, Stathopoulos T (2010) Numerical simulation of dispersion around an isolated cubic building: model evaluation of RANS and LES. Build Environ 45:2231-2239. https://doi.org/10.1016/j. buildenv.2010.04.004

39. Gousseau P, Blocken B, Van Heijst GJF (2013) Quality assessment of large-eddy simulation of wind flow around a high-rise building: validation and solution verification. Comput Fluids 31:1-28

40. Lateb M, Masson C, Stathopoulos T, Bédard C (2014) Simulation of near-field dispersion of pollutants using detached-eddy simulation. Comput Fluids 100:308-320. https://doi.org/10.1016/j.compf luid.2014.05.024

41. Lateb M, Meroney RN, Yataghene M et al (2016) On the use of numerical modelling for near-field pollutant dispersion in urban environments-a review. Environ Pollut 208:271-283. https://doi. org/10.1016/j.envpol.2015.07.039

42. Haupt SE, Zajaczkowski FJ, Peltier LJ (2011) Detached eddy simulation of atmospheric flow about a surface mounted cube at high Reynolds number. J Fluids Eng 133:031002. https://doi. org/10.1115/1.4003649

43. Paik J, Sotiropoulos F, Porté-Agel F (2009) Detached eddy simulation of flow around two wallmounted cubes in tandem. Int J Heat Fluid Flow 30:286-305. https://doi.org/10.1016/j.ijheatfluidflow .2009 .01 .006

44. Blocken B, Stathopoulos T, Carmeliet J, Hensen J (2009) Application of CFD in building performance simulation for the outdoor environment, vol 4, pp 489-496 
45. Janssen WD, Blocken B, Van Wijhe HJ (2017) CFD simulations of wind loads on a container ship: validation and impact of geometrical simplifications. J Wind Eng 166:106-116. https://doi.org/10.1016/j. jweia.2017.03.015

46. Cheng Y, Lien FS, Yee E, Sinclair R (2003) A comparison of large Eddy simulations with a standard $\mathrm{k}-\varepsilon$ Reynolds-averaged Navier-Stokes model for the prediction of a fully developed turbulent flow over a matrix of cubes. J Wind Eng Ind Aerodyn 91:1301-1328. https://doi.org/10.1016/j.jweia .2003.08.001

47. Lübcke H, Schmidt S, Rung T, Thiele F (2001) Comparison of LES and RANS in bluff-body flows. J Wind Eng Ind Aerodyn 89:1471-1485. https://doi.org/10.1016/S0167-6105(01)00134-9

48. Hayati AN, Stoll R, Kim JJ et al (2017) Comprehensive evaluation of fast-response, Reynolds-averaged Navier-Stokes, and large-eddy simulation methods against high-spatial-resolution wind-tunnel data in step-down street canyons. Bound-Layer Meteorol 164:217-247. https://doi.org/10.1007/s1054 6-017-0245-2

49. Rodi W (1997) Comparison of LES and RANS calculations of the flow around bluff bodies. J Wind Eng Ind Aerodyn 69-71:55-75. https://doi.org/10.1016/S0167-6105(97)00147-5

50. Gnatowska R (2011) Aerodynamic characteristics of three-dimensional surface-mounted objects in tandem arrangement. Int J Turbo Jet Engines 28:21-29. https://doi.org/10.1515/TJJ.2011.004

51. Gnatowska R (2015) A study of downwash effects on flow and dispersion processes around buildings in tandem arrangement. Pol J Environ Stud 24:1571-1577. https://doi.org/10.15244/pjoes/40272

52. Frank J, Hellsten A, Schlünzen H, Carissimo B (2007) Best practice guideline for the CFD simulation of flows in the urban environment. COST action 732. Quality Assurance and Improvement of Meteorological Models. University of Hamburg, Meteorological Institute, Center of Marine and Atmospheric Sciences

53. Jarża A, Gnatowska R (2006) Interference of unsteady phenomena in flow around bluff-bodies arrangement. Chem Process Eng Inz Chem Proces 27:721-735

54. Yamartino RJ, Wiegand G (1986) Development and evaluation of simple models for the flow, turbulence and pollutant concentration fields within an urban street canyon. Atmos Environ 20:2137-2156

55. Zhang A, Gao C, Zhang L (2005) Numerical simulation of the wind field around different building arrangements. J Wind End Ind Aerodyn 93:891-904. https://doi.org/10.1016/j.jweia.2005.09.001

56. Zhang A, Gu M (2008) Wind tunnel tests and numerical simulations of wind pressures on buildings in staggered arrangement. J Wind Eng Ind Aerodyn 96:2067-2079. https://doi.org/10.1016/j.jweia .2008 .02 .013

57. Alam MM, Elhimer M, Wang L et al (2018) Vortex shedding from tandem cylinders. Exp Fluids 59:60. https://doi.org/10.1007/s00348-018-2501-8

58. Sobczyk J, Wodziak W, Gnatowska R et al (2018) Impact of the downstream cylinder displacement speed on the hysteresis limits in a flow around two rectangular objects in tandem-PIV study of the process. J Wind Eng Ind Aerodyn 179:184-189. https://doi.org/10.1016/j.jweia.2018.05.022 